\title{
Bilateral Renal Agenesis
}

National Cancer Institute

\section{Source}

National Cancer Institute. Bilateral Renal Agenesis. NCI Thesaurus. Code C101219.

A cong enital abnormality characterized by the absence of both kidneys. 